\title{
Exploration of biomolecules from Pisolithus tinctorius (Pers.) against major soil- borne plant pathogens
}

\author{
P. Ganesh, A.S. Krishnamoorthy», C. Sangeetha, S. Nakkeeran, G. Thiribhuvanamala and S.B. Akshaya \\ *Department of Plant Pathology, CPPS, Tamil Nadu Agricultural University, Coimbatore-641003, Tamil Nadu, India
}

\section{Article Info}

Article history

Received 30 March 2021

Revised 19 May 2021

Accepted 20 May 2021

Published online 30 June 2021

\section{Keywords}

Fruiting bodies

Gas Chromatography

Mass Spectrometry

Mycelium

Pisolithus tinctorius (Pers.)

MTP1

Soil-borne

Plant pathogens

\begin{abstract}
Pisolithus spp. is highly distributed and form mycorrhizal associations with broad range of woody plants in the forest ecosystem. It is more interesting to note that Pisolithus tinctorius is known to form mycorrhizal association with eucalyptus and promotes plant growth. Soil borne plant pathogens are main threat to both agricultural and horticultural crop causing wilt, root rot and seedling blight. P. tinctorius fruiting bodies were collected from eucalyptus plantations at Forest College and Research Institute at Mettupalayam, the morphological characterization studies revealed the presence of deeply rooted stipe bearing yellow to brownish peridium releasing brownish-black basidiospores. As an ecofriendly approach, the present study is focused on exploring biomolecules from P. tinctorius against these pathogens. The bioactive compounds of P. tinctorius MTP 1 isolate was extracted and tested for their inhibitory activity against soil-borne plant pathogens, viz., Fusarium oxysporum f. sp. lycopersici (Sacc.) Synder and Hansen; Macrophomina phaseolina (Goid); Rhizoctonia solani (Kuhn) and Sclerotium rolfsii (Sacc). The ethyl acetate fraction of whole fruiting body (inclusive of basidiospores) extract of P. tinctorius yielded $0.2 \%$ biomolecule composite while, that mycelial mat yielded a negligible quantity of molecules. The biomolecules composite of ethyl acetate fraction of fruiting body at a concentration of $150 \mu \mathrm{l}$ resulted in the maximum inhibition of $R$. solani $\left(840 \mathrm{~mm}^{2}\right)$ when tested by agar well diffusion study. In the case of M. phaseolina and F. o. f. sp. lycopersici, maximum inhibition of $790 \mathrm{~mm}^{2}$ and 680 $\mathrm{mm}^{2}$, respectively was observed. The GC-MS analysis of biomolecules composite of ethyl acetate fraction of sporocarps indicated the presence of compounds belonging to nature of fatty acids, aromatic alcohol, and flavonoid, terpenoids and steroids of antimicrobial nature and suggests exploitation of such molecules in the management of soil-borne plant pathogens.
\end{abstract}

\section{Introduction}

The mycorrhizal association is a symbiotic mutual association between soil fungi and plant root systems. There are several types of mycorrhizal associations, among which arbuscular mycorrhizae and ectomycorrhizae are the most widely distributed. In nature, 83 per cent of dicots, 79 per cent of monocots and all gymnosperms are associated with mycorrhizal fungi (Wilcox et al., 1991). Ectomycorrhizal fungi (ECM) are capable of infecting several arboreous species; thus, this symbiosis is widespread both in temperate and boreal forests and has been proposed to enhance significantly forest production (Smith and Read, 1997). The ECM fungi bring several advantages to plants, including increased root area for absorption, enhanced uptake of nutrients, and drought tolerance (Duddridge et al.,1980). ECM can also help to increase the growth and nutrient contents of plants growing in marginal soil (Jones et al., 1991). Water stress appears to be one of the major causes for the failure of micro-propagated plants during acclimation.

Corresponding author: Dr. A.S. Krishnamoorthy

Professor (Plant Pathology), Tamil Nadu Agricultural University, Coimbatore-641003, Tamil Nadu, India

E-mail: milkmushapk2@gmail.com

Tel.: +91-9790499006
The compatible mycorrhizal fungi in the substrates during the weaning process, not only improve the nutritional status of the plants but also increase their resistance to water stress ex situ, by increasing their weaning rate and reduce the drought stress (Sebastiana et al., 2018). Apart from all these benefits, ECM fungi are well known to protect their host plants from diseases by several means including induced resistance against plant pathogens (Khan et al., 2010). Pisolithus is an ECM fungus that belongs to phylum: Basidiomycota; order: Sclerodermatales and family: Sclerodermataceae. The genus is characterized by conspicuous fruiting bodies with variable shape and size, often with welldeveloped rooting base. Considerable heterogeneity exists within the genus in terms of cultural characters, carpophores, and basidiospore morphology. Several Pisolithus spp. including Pisolithus kisslingi E. Fisch; Pisolithus pusillum Pat. and Pisolithus aurantioscabrosus have been described in tropical South East Asia mainly based on distinctive carpophore and basidiospore morphology (Watling et al., 1995).

Bioactive compounds are widely distributed in the fruiting bodies, mycelium, and culture filtrates of P. tinctorius. Some useful biomolecules obtained from the fruiting bodies of $P$. tinctorius include lanostane-triterpene and naphthalenoid-pulvinic acid derivatives. Zamuner et al. (2005) collected fruting bodies of P. tinctorius from eucalyptus plantation and isolated a new triterpene compound 
called pisosterol from the fruiting bodies. They have also isolated four different lanostanetriterpenoid compounds from the mycelial cultures and fruiting bodies of $P$. tinctorius. Ameri et al. (2011) isolated several bioactive compounds which include diterpenoids, sesquiterpenoids and fractions of polysaccharides, viz., I, II, IIIA, and IIIB from the fruit bodies of $P$. albus. Moreover, reports about the antimicrobial activities of $P$. tinctorius and its role in biological control programmes of plant pathogens are scanty. Most of the literature focused on the possible usage of $P$. tinctorius isolates as ECM fungi with host plants for growth enhancement. Reports on genetic variability, taxonomic phylogeny, soil fertility management, reduction of chaemotoxis and erosion control are also sparsely available ((Zeng et al., 2003). Nevertheless, Shrestha et al. (2005) conducted in vitro studies and reported the antimicrobial potentials of Pisolithus spp. against a spectrum of bacterial pathogens. The metabolites of Pisolithus spp. exhibited greater inhibition against Salmonella typhi, Kleibsiella sp., Bacillus sp., Escherichia coli, Pseudomonas aeruginosa, Agrobacterium tumifaciens, and a low level of inhibition against $S$. aureus and Shigella dysenteriae. The triterpene pisosterol has been shown to have antitumor activity against tumor cell lines, leukemia, and melanoma cells (Montenegro et al., 2004). With these basic backgrounds, the current investigation had been focused mainly to explore the multifaceted molecules of $P$. tinctorius in plant disease management.

\section{Material and Methods}

\subsection{Collection and isolation of fruiting body of $P$. tinctorius}

The fruiting bodies of $P$. tinctorius were collected from eucalyptus plantations at Forest College and Research Institute, Jakkanari Range, Mettupalayam (Latitude: 770 56' E; Longitude:110 19' N; Altitude $300 \mathrm{~m}$ MSL), Coimbatore district, Tamil Nadu (Figure1). The collected sporophores were brought to the laboratory in paper bags. Morphological identification was done by macroscopic and microscopic examination. All the specimens were stored at $4^{\circ} \mathrm{C}$ prior to the isolation and purification of the fungal culture. The small pieces of fruiting bodies cut from the gleba were surface sterilized with 70 per cent of ethanol for 2 min followed by 0.1 per cent sodium hypocloride for one min and then rinsed four times with sterile water. Sterilized pieces of Pisolithus were kept in a special medium under room temperature.

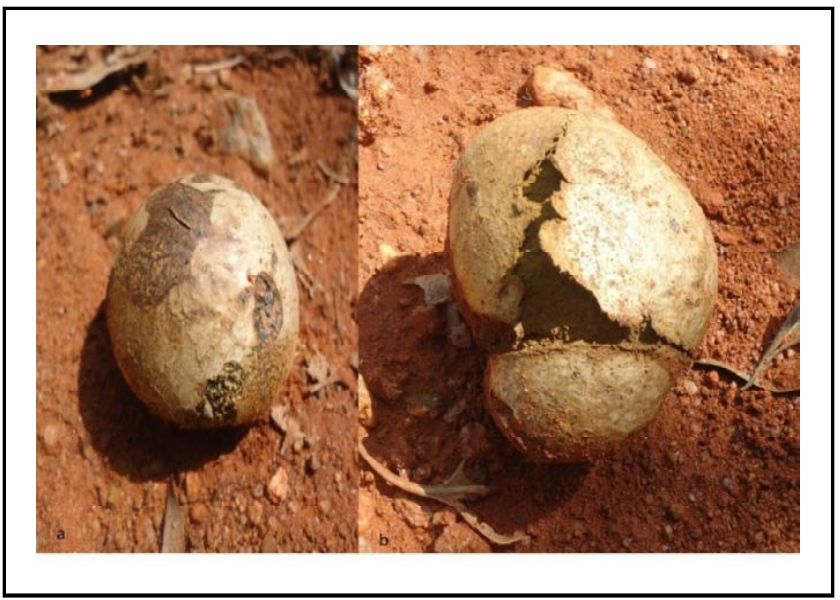

Figure 1: Pisolitus tinctorius isolate MTP1 growing in Eucalyptus plantation.
2.2 Extraction of bioactive compounds from the fruiting bodies of P. tinctorius MTP1

Pisolitus tinctorius MTP1 sporophore samples drawn from the preserved specimen stored at $4^{\circ} \mathrm{C}$ were milled to a fine powder in a mixer blender. Samples weighing $20 \mathrm{~g}$ were extracted with $100 \mathrm{ml}$ of different solvents, viz., chloroform, ethyl acetate, methanol, and water successively with intermittent warming in a waterbath maintained at $55-60^{\circ} \mathrm{C}$. The extracted samples were stored at $28 \pm$ $2^{\circ} \mathrm{C}$ in darkness for $24 \mathrm{~h}$. The process was repeated for the second time. The extractants obtained were pooled together and filtered through a Whatman No.1 filter paper and concentrated to dryness in a rotary evaporator. The condensate was later dissolved in DMSO, filtered through a membrane filter $(0.2 \mu \mathrm{m})$, and stored at $4{ }^{\circ} \mathrm{C}$ for further study.

\subsection{Extraction of bioactive compounds from the mycelia of $P$. tinctorius}

Five $\mathrm{g}$ of freeze-dried mycelia obtained from the submerged cultures of P. tinctorius maintained in MMN broth (pH: 5.5$)$ at $30^{\circ} \mathrm{C}$ for $30 \mathrm{~d}$ in complete darkness were powdered in liquid nitrogen; and extracted three times with diethyl ether used at the rate of one ml each time. The extracted sample was taken in the Eppendorf tubes of $2 \mathrm{ml}$ capacity and was centrifuged at $10,000 \mathrm{~g}$ for $5 \mathrm{~min}$ in a bench centrifuge (stored at $4^{\circ} \mathrm{C}$ ).

\subsection{Bioassay of whole fruiting body extracts}

Twenty $g$ of the samples were drawn out from the powdered sporocarps and extracted with $100 \mathrm{ml}$ of organic solvents viz., chloroform, ethyl acetate, methanol, and water, as described in the bioassay of different solvents fraction of secondary metabolites.

\subsection{Gas chromatography - mass spectrometry (GC-MS)}

Characterization of biomolecules extracted from fruiting bodies and mycelia was done by GC-MS analysis. Volatile components were identified by GC-MS using a column Elite-5MS (100\% Dimethylpolysiloxane), $30 \times 0.25 \mathrm{~mm} \times 0.25 \mu \mathrm{m}$ df equipped with GC Clarus 500 Perkin Elmer. The turbo mass-gold-perkin- Elmer detector was used. The carrier gas flow rate was $1 \mathrm{ml} \mathrm{min}-1$, split 10:1, and injected volumes were $3 \mu$. The column temperature was maintained initially at $110^{\circ} \mathrm{C}$ at the rate of $10^{\circ} \mathrm{C} \mathrm{min}^{-1}$. No hold followed by an increase up to $280^{\circ} \mathrm{C}$ at the rate of $5^{\circ} \mathrm{C} / \mathrm{min}^{-9}$ (hold). The injector temperature was $250^{\circ} \mathrm{C}$ and this temperature was held constant for $36 \mathrm{~min}$. The electron impact energy was $70 \mathrm{eV}$, Juliet line temperature was set at $2000^{\circ} \mathrm{C}$ and the source temperature was set at $200^{\circ} \mathrm{C}$. Electron impact (EI) mass scan $(\mathrm{m} / \mathrm{z})$ was recorded in the 45-450 aMU range. Using computer searches on the NIST Version 2011 MS data library and comparing the spectrum obtained through GC/MS, the compounds present in the crude sample were identified.

\subsection{Statistical analyses}

Statistical analyses of all the experiments were conducted using the following methods suggested by Gomez and Gomez, (1984). The mean differences were adjusted with Duncan's Multiple Range Test (DMRT) using the statistical computer package program, IRRISTAT version- 92 developed by the International Rice Research Institute Biometrics unit, the Philippines. 


\section{Results}

Soil-borne plant pathogens are known to infect several economically important crops and bring about huge yield loss. The impediments in using fungicides to control these pathogens include residual toxicity, health hazard, and environmental pollution. On the other hand, the use of biodegradable antifungal organic compounds of microbial origin, more specifically, those compounds obtained from macro-fungi will have a greater attraction in crop disease management. In the current investigation, some of the bioactive compounds of the macro-basidiomycete $P$. tinctorius have been separated and their efficacies were tested against soil-borne plant pathogens viz., F. o.f. sp. lycopersici, M. phaseolina, R. solani, and $S$. rolfsii. The results are presented below.

\subsection{Morphological characterization of $P$. tinctorius MTP1}

Morphological and microscopic characters of fruiting bodies found under eucalyptus plantations at Forest College and Research Institute, Mettupalayam, Jakkanari Forest Range, Coimbatore district, Tamil Nadu were examined. The shape of the fruiting bodies varied from globose to subglobose; 4 to $7 \mathrm{~cm}$ in diameter. The total length of the sporocarp varied from 3.0 to $8.5 \mathrm{~cm}$. Sometimes the basidiocarps were deeply rooted with yellowish fibrous stipe measuring $2 \mathrm{~cm}$ in diameter. On average, the stipe length was $3 \mathrm{~cm}$. The peridium was thin-walled with bright yellow-to-yellowishbrown or blackish/olive green tone. The texture of peridium varied from fleshy to slightly viscid in juvenile stages. The peridium was fragile and pulvinate at maturity. The gleba and peridioles had pale white, yellowish-brown, or olivaceous powdery spore mass. Breakdown of round and smooth peridioles resulted in the release of clouds of basidiospores. The spores were spherical, 7 to $8 \mu \mathrm{m}$ in diameter with ornamentations up to $0.5 \mu \mathrm{m}$. Constituent hyphae were thin and thick-walled measuring approximately $2-3 \mathrm{~mm}$ in diameter. Hyphae were hyaline to brown (Figure 2).

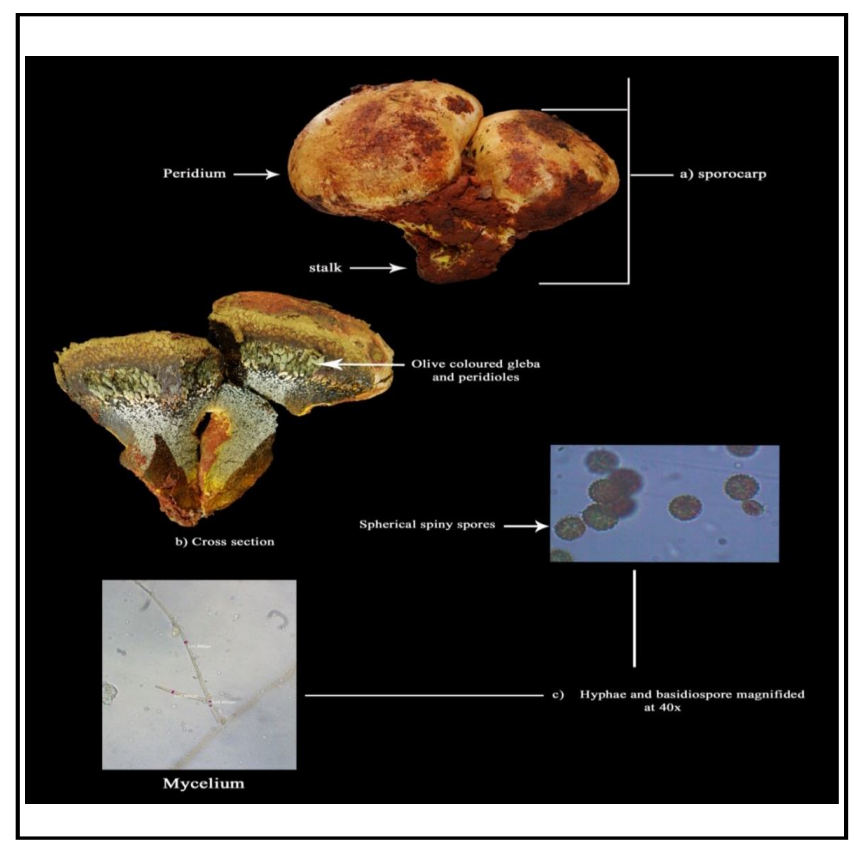

Figure 2: Morphology of Pisolithus tinctorius isolate MTP1.
3.2 Extraction of bioactive compounds from P. tinctorius isolates MTP1

Bioactive compounds were extracted from the whole fruiting bodies of $P$. tinctorius isolate MTP1 utilizing different solvents, viz., ethyl acetate, methanol, chloroform, diethyl ether, and water. Per cent recovery of substance (calculated in terms of w/v) from the whole fruiting body is presented in Table 1 . From $20 \mathrm{~g}$ of fruiting body sample, $40 \mathrm{mg}$ of ethyl acetate fraction; $32 \mathrm{mg}$ of methanol fraction; $28 \mathrm{mg}$ of chloroform fraction, and $10 \mathrm{mg}$ of water evaporated residue were obtained. A maximum level of $0.04 \%$ recovery was observed when ethyl acetate was used as the solvent. When methanol and chloroform were used, the recovery levels were 0.032 and $0.028 \%$. But, when water alone was used to dissolve the sample, only $0.01 \%$ residue could be recovered after evaporation. Similarly, diethyl ether was used as the solvent for extracting compounds from the mycelial mat. However, the recovery percent was negligible.

\subsection{Effect of ethyl acetate fraction of fruiting bodies}

The antifungal nature of the bioactive compound of $P$. tinctorius in its crude was tested separately against $F$. $o$. f. sp. lycopersici, $R$. solani, M. Phaseolina, and $S$. rolfsii by agar well diffusion method at 50,100 , and $150 \mu$ concentrations. The results showed that the ethyl acetate fractions of $P$. tinctorius sporocarp-based bioactive compounds were more inhibitory to $R$. solani $\left(840 \mathrm{~mm}^{2}\right)$ as compared M. phaseolina $\left(790 \mathrm{~mm}^{2}\right)$ and F. o. f. sp. lycopersici $(680$ $\mathrm{mm}^{2}$ ) when used at a concentration of $150 \mu \mathrm{l}$. This fraction of the bioactive compound was also not found to inhibit $S$. rolfsii (Table 2).

3.4 Characterization of bioactive compounds of CFC filtrate condensate, fruiting body, and mycelial mat through GCMS

The ethyl acetate fraction of whole fruiting bodies (including basidiospores) and diethyl ether fraction of mycelial mat were subjected to GC-MS analysis. The results showed an array of biomolecules as tabulated in Tables 3 and 4 . The biomolecules composite of sporocarps contained several volatile compounds like hexadeconic acid; 2-penta-deuterio-isopropenyl-3-heptadeuterio-isopropyl naphthalene; tetrakis-dimethyl-silylcarbodiimide); di-(2-ethylhexyl) phthalate and Hesperetin (1-[2,4,6tris (trimethylsiloxy) phenyl] 3- [3-methoxy-4-(trimethylsiloxy) phenyl] - 2- propen - 1-one) (Figure 3 and Table 3).

Table 1: Per cent recovery of bioactive compounds from fruit bodies of $P$. tinctorius.

\begin{tabular}{|l|l|l|}
\hline \multirow{2}{*}{ Solvent used @100 ml } & \multicolumn{2}{|c|}{ Fruit bodies } \\
\cline { 2 - 3 } & $\mathbf{( m g )}$ & Per cent \\
\hline Ethyl acetate & 40 & 0.04 \\
\hline Methanol & 32 & 0.032 \\
\hline Chloroform & 28 & 0.028 \\
\hline Water & 10 & 0.01 \\
\hline
\end{tabular}

*Each sample of biomolecules mixture was weighed after condensing the solvents in a vacuum flask evaporator at $45^{\circ} \mathrm{C}$ for $30 \mathrm{~min}$. 
Table 2: Effect of various fractions of bioactive molecules of $P$. tinctorius (fruiting bodies) against different soil-borne plant pathogens

\begin{tabular}{|c|c|c|c|c|c|}
\hline \multirow[b]{2}{*}{ Bioactive molecules } & \multirow[b]{2}{*}{ Concentrations $(\mu \mathrm{l})$} & \multicolumn{4}{|c|}{ Inhibition $\left(\mathbf{m m}^{2}\right)$} \\
\hline & & $\begin{array}{c}\text { F.oxysporum } \\
\text { f. sp. lycopersici }\end{array}$ & M. phaseolina & R. solani & S. rolfsii \\
\hline \multirow{3}{*}{ Ethyl acetate fraction } & 50 & $310.00^{\mathrm{c}}(17.64)$ & $420.00^{\mathrm{c}}(20.52)$ & $330^{\mathrm{c}}(18.20)$ & $0.00(1.12)$ \\
\hline & 100 & $470.00^{\mathrm{b}}(21.70)$ & $540.00^{\mathrm{b}}(23.26)$ & $620^{\mathrm{b}}(24.95)$ & $0.00(1.12)$ \\
\hline & 150 & $680.00^{\mathrm{a}}(26.70)$ & $790.00^{\mathrm{a}}(28.13)$ & $840^{\mathrm{a}}(29.00)$ & $0.00(1.12)$ \\
\hline \multirow{3}{*}{ Methanol fraction } & 50 & $0.00(1.12)$ & $0.00(1.12)$ & $0.00(1.12)$ & $0.00(1.12)$ \\
\hline & 100 & $0.00(1.12)$ & $0.00(1.12)$ & $0.00(1.12)$ & $0.00(1.12)$ \\
\hline & 150 & $0.00(1.12)$ & $0.00(1.12)$ & $0.00(1.12)$ & $0.00(1.12)$ \\
\hline \multirow{3}{*}{ Chloroform fraction } & 50 & $0.00(1.12)$ & $0.00(1.12)$ & $0.00(1.12)$ & $0.00(1.12)$ \\
\hline & 100 & $0.00(1.12)$ & $0.00(1.12)$ & $0.00(1.12)$ & $0.00(1.12)$ \\
\hline & 150 & $0.00(1.12)$ & $0.00(1.12)$ & $0.00(1.12)$ & $0.00(1.12)$ \\
\hline \multirow{3}{*}{ Water residue } & 50 & $0.00(1.12)$ & $0.00(1.12)$ & $0.00(1.12)$ & $0.00(1.12)$ \\
\hline & 100 & $0.00(1.12)$ & $0.00(1.12)$ & $0.00(1.12)$ & $0.00(1.12)$ \\
\hline & 150 & $0.00(1.12)$ & $0.00(1.12)$ & $0.00(1.12)$ & $0.00(1.12)$ \\
\hline Control (+) Sterile water & 150 & $0.00(1.12)$ & $0.00(1.12)$ & $0.00(1.12)$ & $0.00(1.12)$ \\
\hline Control (-) DMSO & 150 & $0.00(1.12)$ & $0.00(1.12)$ & $0.00(1.12)$ & $0.00(1.12)$ \\
\hline $\mathrm{CD}$ & & 136 & 158 & 168 & 0.0 \\
\hline
\end{tabular}

Values in parentheses are square-root transformed, means followed by a common letter is not significantly different by DMRT ( $p=0.05$ per cent).

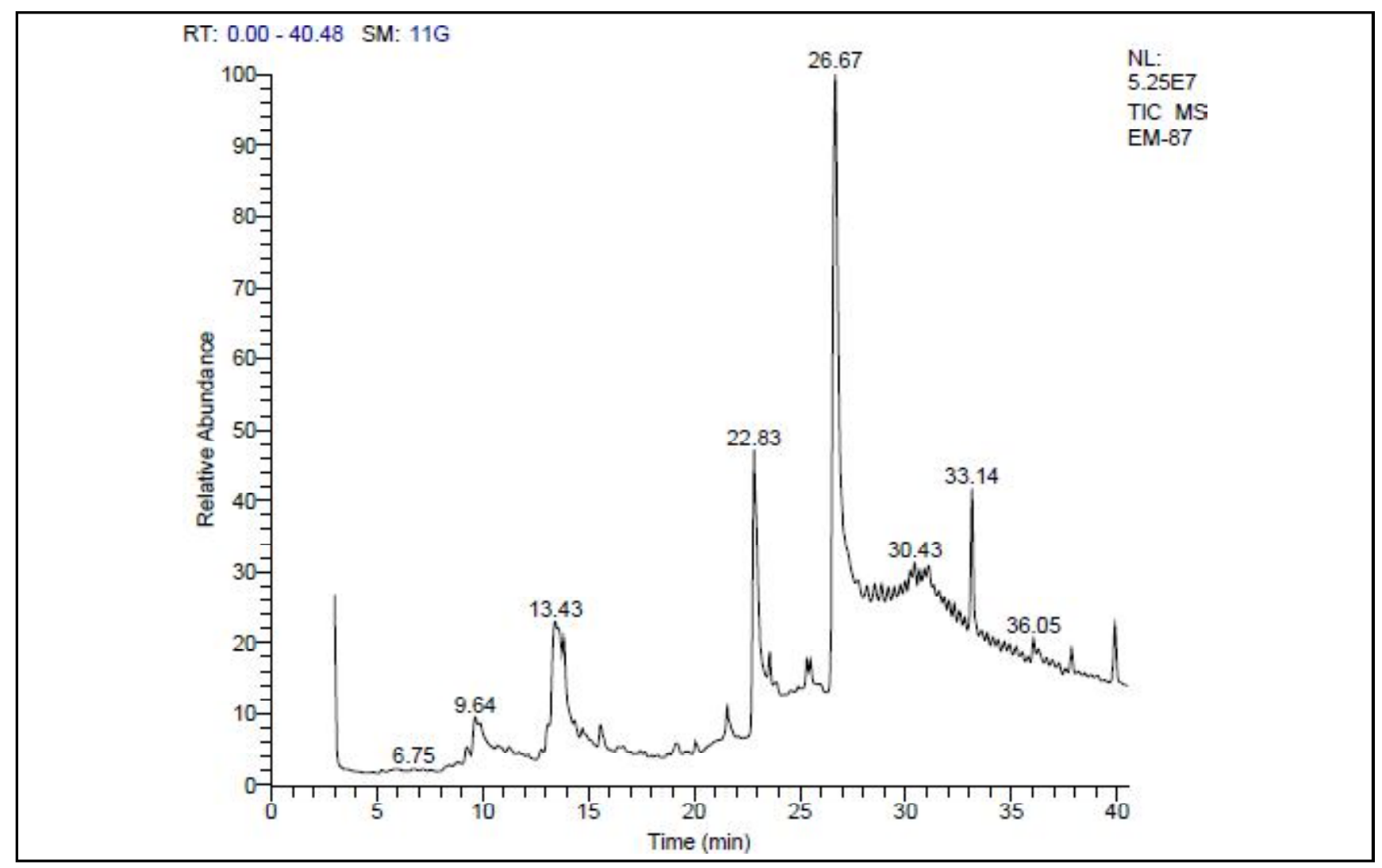

Figure 3: Total ion chromatogram (TIC) of biomolecules identified from fruiting bodies of P. tinctorius through GC-MS. 
Table 3: GC-MS analysis of fruiting body extract (ethyl acetate fraction) of $P$. tinctorius

\begin{tabular}{|c|c|c|c|c|c|c|}
\hline $\mathbf{R T}^{*}$ & Compound & Structure & $\begin{array}{l}\text { Molecular } \\
\text { formula }\end{array}$ & MW* & $\begin{array}{l}\text { Peak } \\
\text { area }(\%)\end{array}$ & $\begin{array}{l}\text { Nature of } \\
\text { compounds }\end{array}$ \\
\hline 22.83 & Hexadecanoic acid & & $\mathrm{C}_{16} \mathrm{H}_{32} \mathrm{O}_{2}$ & 256 & 10.98 & Fatty acid \\
\hline 26.67 & $\begin{array}{l}\text { 2Pentadeuterioisopropenyl- } \\
\text { 3heptadeuterioisopropy } \\
\text { lnaphthalene }\end{array}$ & & $\mathrm{C}_{16} \mathrm{H}_{6} \mathrm{D} 12$ & 210 & 35.18 & Not known \\
\hline 30.43 & $\begin{array}{l}\text { Tetrakis (Dimethylsilyl- } \\
\text { carbodiimide) }\end{array}$ & fied & $\mathrm{C}_{12} \mathrm{H}_{24} \mathrm{~N}_{8} \mathrm{Si}$ & 392 & 2.09 & Not known \\
\hline 33.14 & Di-(2-ethylhexyl)phthalate & & $\mathrm{C}_{24} 4 \mathrm{H}_{38} \mathrm{O} 4$ & 390 & 5.16 & Not known \\
\hline 36.05 & $\begin{array}{l}\text { 1-[2,4,6-tris(trimethylsiloxy) } \\
\text { phenyl]- 3-[3-methoxy-4- } \\
\text { (trimethylsiloxy)phenyl]-2- } \\
\text { propen-1-one (Hesperetin) }\end{array}$ & & $\mathrm{C}_{28} \mathrm{H}_{46} \mathrm{O}_{6} \mathrm{~S}_{\mathrm{i}} 4$ & 590 & 1.02 & Flavanoids \\
\hline
\end{tabular}

*RT-Retention time; *MW-Molecular weight.

Likewise, diethyl ether fraction of mycelial mat contained cyclohexane, 1,4-dimethyl-2-octadecyl-, methyl -2- (3', 3' - dimethyl - 1' - butyn - 1' - yl ) -1 cyclohexene carboxylate, 7, 9 - di-tert-butyl-1 oxaspiro (4,5) deca -6, 9 - diene -2, 8-dione (Figure 4 and Table 4).

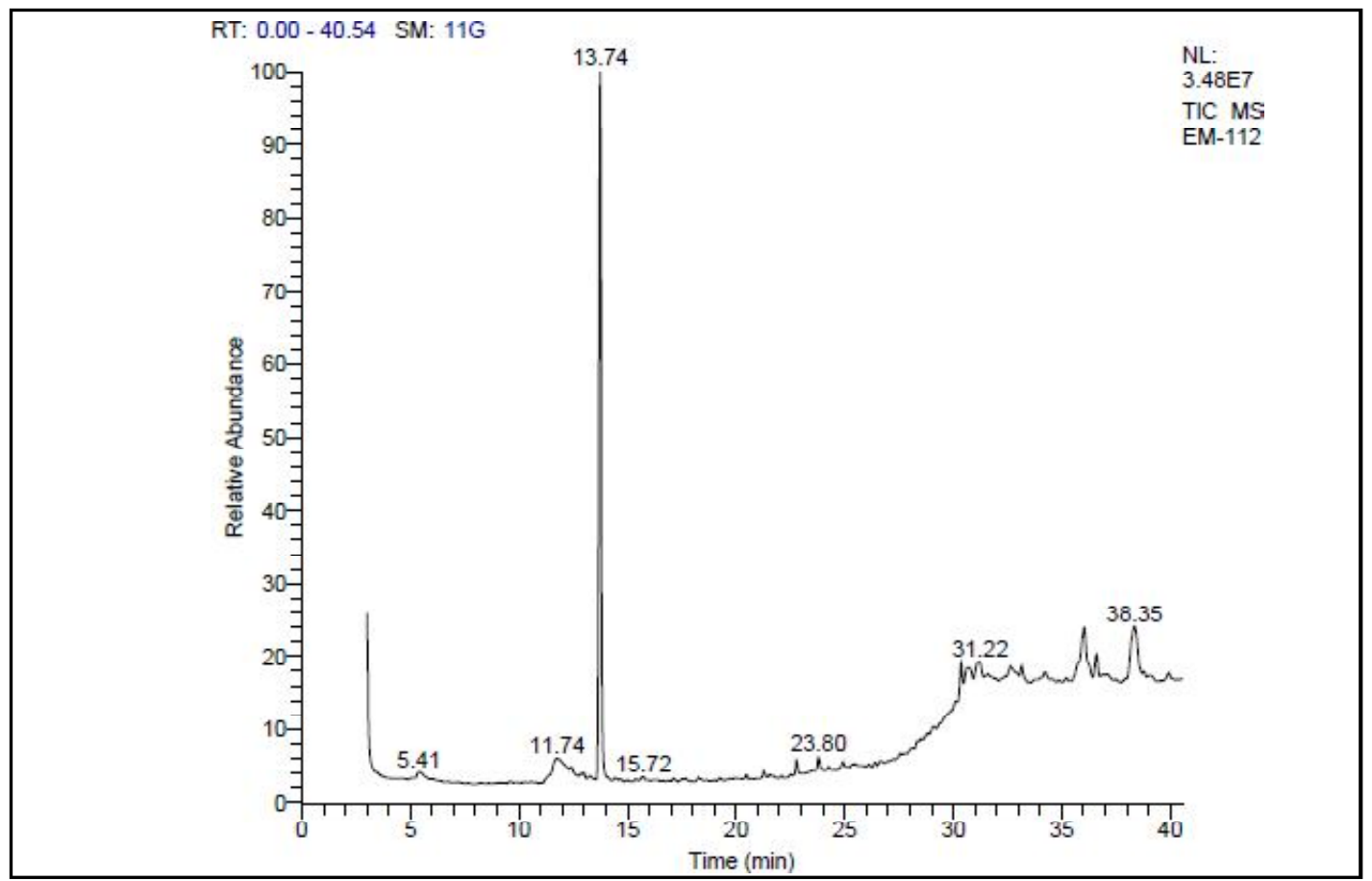

Figure 4: Total ion chromatogram (TIC) of biomolecules identified from mycelial mat of $P$. tinctorius through GC-MS. 
Table 4: GC-MS analysis of mycelial mat (diethyl ether extract) of $P$. tinctorius

\begin{tabular}{|c|c|c|c|c|c|c|}
\hline $\mathbf{R T}^{*}$ & Compound & Structure & $\begin{array}{l}\text { Molecular } \\
\text { formula }\end{array}$ & MW* & $\begin{array}{l}\text { Peak area } \\
\text { Per cent }\end{array}$ & $\begin{array}{l}\text { Nature of } \\
\text { compounds }\end{array}$ \\
\hline 5.41 & $\begin{array}{l}\text { Cyclohexane, 1,4-dimethy } \\
\text { 1- 2-octadecyl }\end{array}$ & & $\mathrm{C}_{26} \mathrm{H}_{52}$ & 364 & 1.48 & Terpenoid \\
\hline 13.74 & $\begin{array}{l}\text { Methyl } 2-(3 ', 3 \text { '-dimethyl-1'- } \\
\text { butyn-1'-yl)-1 cyclohexene- } \\
\text { carboxylate }\end{array}$ & & $\mathrm{C}_{14} \mathrm{H}_{20} \mathrm{O}_{2}$ & 220 & 42.42 & Terpenoid \\
\hline 23.80 & $\begin{array}{l}\text { 7,9-Di-tert-butyl-1- oxaspiro } \\
(4,5) \text { deca-6, 9-diene- } 2,8 \text {-dione }\end{array}$ & & $\mathrm{C}_{17} \mathrm{H}_{24} \mathrm{O}_{3}$ & 276 & 0.80 & Steroid \\
\hline
\end{tabular}

RT*- Retention time; MW*-Molecular weight.

\section{Discussion}

Soil-borne plant pathogens are very difficult to destroy because their inoculums survive in the soil throughout the year even absence of host. Several fungicides are available in market but no one could control the pathogen completely with recommended dose. The farmers are using a lot of pesticides with high concentration that has led to environmental pollution and health hazards as well the high cost of production. Keeping all these constrain in mind, the current investigation is mainly focused on search of noval antimicrobial compounds from the beneficial fungi to develop biopesticides. Some of the novel compounds were initiated and tested against soil-borne plant pathogens, viz., F. o. f. sp. lycopersici, $M$. phaseolina, $R$. solani and $S$. rolfsii. The results obtained are discussed hereunder.

\subsection{Morphological characterization of $P$. tinctorius isolate MTP1}

Macro and micro morphological differences, in carpophores; and of isolated cultures, have been observed in P. tinctorius in several countries. The basidiomes of $P$. tinctorius exhibit polymorphism and vary greatly in size, shape, diameter, and colour of glebal chambers and nature of the exterior of the peridium, but are commonly characterized by globose basidiospores, $7-12 \mu \mathrm{m}$ in diameter covered with densely packed spines up to $1.5 \mu \mathrm{m}$ in length. However, an examination of basidiospores collected from North America, Europe, Africa, and Australia had revealed three distinct basidiospore types (Grand, 1976). Moreover, Burgess et al. (1995) had reported that basidiomes from Western Australia, New South Wales and Queensland varied considerably in size (2$20 \mathrm{~cm}$ ), shape (globose, pyriform, ellipsoid), length and type of sterile stipe (absent, short, well developed with rhizome, long and woody); and peridium features (smooth, cracked, rugulose, striated, patchy). Two new species of Pisolithus, namely; Pisolithus aurantioscabrosus collected under Shorea macroprera from Malaysia (Martin et al., 2002) and P. adbitus collected under Dipterocarpus alatus from Thailand (Kanchanaprayudh et al., 2003) have been described from dipterocarp forests. These reports on morphological variability suggest that $P$. tinctorius is taxonomically more diverse than currently recognized, and needs further taxonomic revision. Reddy et al. (2005) identified a new species of Pisolithus indicus, which to forms ectomycorrhizal association with dipterocarps of native forests in India. The preliminary morphological observations of $P$. tinctorius isolate, MTP1 is similar to $P$. indicus reported by Reddy et al. (2005) and Cullings et al. (2020). But, the Annual report of the Institute of Forest Genetics and Tree Breading (IFGTB), Coimbatore for the year 2003-2004 indicates that the ectomycorrhizal fungus found in association with Eucalyptus plantation from the same geographical coordinates at Mettupalayam as $P$. tinctorius. Taking this report as strong evidence, Pisolithus isolate MTP1 is rightly placed under the species "tinctorius".

\subsection{Extraction and recovery of biomolecules from P. tinctorius isolate MTP1}

In the present study, biomolecules were extracted from the whole fruiting body inclusive of basidiospores and mycelial mat using different solvents and water. After, a series of extraction processes, the per cent recovery of biomolecules in solvent and water fractions was calculated on a dry weight basis. Ethyl acetate fraction of the samples was always found to give the maximum recovery of biomolecules $(0.2 \%$ from whole fruiting bodies). In a similar study, Ameri et al. (2011) reported that the ethyl acetate fraction of the sporocarps of Pisolithus albus exhibited increased levels of recovery of biomolecules (up to $40 \mathrm{mg}$ per $100 \mathrm{ml}$ of solvent which is equivalent to 0.4 per cent). The poor recovery of biomolecules in water fraction indicates that the composite biomolecules do not dissolve in an aqueous solution. As the recovery percentage of biomolecules from the mycelial mat was very minimum $(0.0010$ percent), no further experiment was conducted using this composite; but, it was subjected to GC-MS analysis, just for profiling the compounds that were present in it.

\subsection{Effects of ethyl acetate fraction of bioactive molecules of P. tinctorius isolate MTP1}

Bioactive compounds were found to be diversely distributed in the fruiting bodies and the mycelial mat of $P$. tinctorius. Among the different solvents used for extraction and recovery of bioactive compounds, ethyl acetate fractions of fruiting body extract had exhibited considerable antifungal activity against $F$. $o$. f. 
sp. lycopersici, M. phaseolina, and $R$. solani whereas, methanol, chloroform, and aqueous extracts were not effective in controlling any of the test pathogens. The results also indicated the ineffectiveness of even the ethyl acetate fraction against $S$. rolfsii. More interestingly, the ethyl acetate fraction of whole fruiting body extract showed only $680 \mathrm{~mm}^{2}$ inhibition against $F$. o. f. sp. lycopersici. And in the case of $R$. solani and M. phaseolina, whole fruiting body extracts showed only $840 \mathrm{~mm}^{2}$ and $790 \mathrm{~mm}^{2}$ inhibition, respectively. The reason for this differential expression of antimicrobial activities might be due to the differences in the bioactive compositions, concentrations, methods of extraction, and mechanism of action of the available active ingredients. Imtiaj and Lee (2007) also reported that the ethanol extract of non-edible macrofungi, Stereum ostrea had contained antifungal properties against certain plant pathogenic fungi including Colletotrichum gloeosporioides, C. miyabeanus, and Botrytis cinerea; and the extract was found to significantly reduce the mycelial growth of the pathogenic fungi.

In a similar study, Shrestha et al. (2005) reported the antibacterial activity of metabolites of Pisolithus spp against a spectrum of Gram-negative and Gram-positive bacteria. Ameri et al. (2011) also concluded that the ethyl acetate fractions of the sporocarps of P. albus showed the maximum inhibition for Staphylococcus aureus. Earlier, Waser (2002) reported that many of the macrofungi had contained bioactive compounds, with antifungal, antibacterial and antiviral activities. In a separate study, the methanol extract of Phellinus was reported to possess better antifungal potentials than aqueous extract (Balakumar et al., 2011). The methanol extract was found to significantly inhibit the mycelial growth of five fungal pathogens, viz., Penicillium sp., Aspergillus fumigatus, A. niger, A. flavus, and Mucor indicus.

\subsection{Characterization of bioactive compounds through GC-MS}

The ethyl acetate fraction of the whole fruiting body (including basidiospores) and diethyl ether fraction of mycelial mat was subjected to GC-MS analysis and the result revealed that fruiting body and mycelia mat contained compounds, viz., hexadecanoic acid; 2Pentadeuterioisopropenyl-3heptadeuterioisopropylnapht halene; Tetrakis (Dimethylsilylcarbodiimide); Di-(2-ethylhexyl) phthalate and 1-[2,4,6-tris(trimethylsiloxy) phenyl]-3-[3-methoxy4- (trimethylsiloxy) phenyl] -2- propen-1-one (Hesperetin). Among these, benzene-ethanol $(0.25$ per cent $)$ is aromatic alcohol expressed at 7.85 RT (Retention time). Fraud et al. (2003) had observed antioxidant and antibacterial activity of this compound against certain Gram-negative bacteria and mycobacteria.

Nevertheless, the biomolecules composite of sporocarps of $P$. tinctorius contained several other organic compounds including hexadecanoic acid, a fatty acid fraction ( 10.98 per cent) was identified at 22.83 RT. Praveen Kumar et al. (2010) reported that hexadecanoic acid had acted as an antioxidant, hypocholesterolemic, nematicide, pesticide, anti-androgenic flavor compound, hemolytic, and 5-alpha reductase inhibitor. The biological activity of 2-Penta-deuterioisopropenyl-3-hepta-deuterio-isopropyl naphthalene (35.18 percent) found to be expressed at $26.67 \mathrm{RT}$ is not known. Likewise, tetrakis (dimethylsilylcarbodimide) found expressed to a limited extent of up to 2.09 per cent at 30.43 RT has already been reported to induce severe salt tolerance in tomato plants when applied through the foliage. Hence, it is assumed that the symbiotic association of $P$. tinctorius would help its host to withstand any of the physiological stress. This concept is further supported by the fact that Eucalyptus is known for its stress tolerance; and P. tinctorius was always found to be in association with Eucalyptus plantations. At 33.14 RT a compound namely, di-(2-ethylhexyl) phthalate was found to be meagrely expressed (up to 5.16 percent). However, Habib and Karim (2009) reported about the antifungal activity of di-(2-ethylhexyl) phthalate against A. flavus, A. niger, and a Fusarium sp. Another phenolic compound namely, hesperetin (1-[2,4,6-tris (trimethylsiloxy) phenyl] 3- [3-methoxy4-(trimethylsiloxy) phenyl] -2- propen-1-one) was found to be expressed up to 1.02 per cent at 36.05 RT. Zaat et al. (1989) reported that this compound had induced nodulation in leguminous plants.

In addition, certain terpenoids and steroidal compounds such as cyclohexane 1,4-dimethyl-2-octadecyl; methyl -2- (3', 3' - dimethyl - 1' - butyn - 1' - yl ) -1 cyclohexene carboxylate; 7, 9 - di-tert-butyl1 oxaspiro $(4,5)$ deca $-6,9$ - diene -2, 8-dione were identified from the diethyl ether fraction of mycelial mat. Cyclohexane, carboxylic acid, and diene compounds are more valuable and major components of many of the pharmaceutical and pesticidal preparations (Praveen Kumar et al., 2010). Further studies to recover these useful compounds in large quantities from $P$. tinctorius will have multifaceted benefits. Interestingly, several unknown compounds were also found expressed during GC-MS analysis; and their potential role in inhibiting the test pathogens, viz., F. o. f. sp. lycopersici, $M$. phaseolina, $R$. solani, and even $S$. rolfsii need to be elucidated. Conclusively, the results of the present investigations reveal evidence that the bioactive compounds of $P$. tinctorius isolate MTP1 could be potentially explored for the management of soil-borne plant pathogens that induce wilt, root rot, and sheath blight diseases in crop plants. Also, such compounds may be useful in plant growth promotion, quorum sensing, nodulation, and stress tolerance.

\section{Conclusion}

The current study revealed the antifungal potential of bioactive compounds of $P$. tinctorius isolate MTP1 against soil borne plant pathogens, viz., F. oxysporum f. sp. lycopersici, M. phaseolina, $R$. solani and $S$. rolfsii. The ethyl acetate fraction of whole fruiting body (inclusive of basidiospores) extract yielded $0.2 \%$ biomolecule composite that could have maximum inhibition of $R$. solani $(840$ $\left.\mathrm{mm}^{2}\right)$, M. phaseolina $\left(790 \mathrm{~mm}^{2}\right)$, and $F$. oxysporum $\mathrm{f}$. sp. lycopersici colony $(680 \mathrm{~mm})$. Characterization of biomolecules through GC-MS indicated the presence of antimicrobial compounds that belonged to the nature of fatty acids, aromatic alcohol, terpenoids, steroids, and flavonoids. Further study is warranted to explore the mode of action of these biomolecules against plant pathogens.

\section{Acknowledgments}

The authors thank the University and ICAR AICRP Mushroom Scheme for supporting this study.

\section{Conflict of interest}

The authors declare that there are no conflicts of interest relevant to this article. 


\section{References}

Ameri,A.; Ghadge, C.; Vaidya, G.J. and Deokule, S.S. (2011). Anti-Staphylococcus aureus activity of Pisolithus albus from Pune, India. J. of Medicinal Plants Res., 5:527-532.

BalaKumar, R.; Sivaprakasam, E.; Kavitha, D.; Sridhar, S. and Kumar, J.S. (2011) Antibacterial and antifungal activity of fruiting bodies of Phellinus mushroom extract. International Journal of Biosciences, 1(3):72-77.

Burgess, T.; Pascal, L.; Dell, B.; Malajczuk, N. and Martin, F. (1995). Effect of fungalisolate aggressivity on the biosynthesis of symbiotic-related polypeptides in differentiating eucalypt ectomycorrhizas. Planta, 195:408-417.

Cullings, K.; Stott, M. B.; Marinkovich, N.; Desimone, J. and Bhardwaj, S. (2020) Phylum-level diversity of the microbiome of the extremophilic basidiomycete fungus Pisolithus arhizus (Scop.) Rauschert: An island of biodiversity in a thermal soil desert. Microbiol., 9(8):1-16.

Duddridge, J. A.; Malibari, A and Read, D. J. (1980). Structure and function of mycorrhizal rhizomorphs with special reference to their role in water transport. Nature, 287:834-836.

Fraud, S.; Ress, E. L.; Mahenthiralingam, E.; Russell, A. D. and Maillard, J. Y. (2003). Aromatic alcohols and their effect on bacteria, cocci and mycobacteria. J. Chemother., 51:1435-1436.

Gomez, K.A. and Gomez, A.A. (1984). Statistical Procedure for Agricultural Research. John Wiley and Sons, New York, NY, USA.

Grand, L.F.(1976). Distribution, plant associates and variation in the basidiocarps of Pisolithus tinctorius in the United States. Mycologia, 68:672-.678.

Habib, R. M. and Karim, R. M. (2009). Antimicrobial and cytotoxic activity of Di-(2-ethylhexyl) phthalate and anhydrosophoradiol-3-acetate Isolated from Calotropis gigantea (Linn.) flower. Mycobiology, 37(1):31-36.

Imtiaj, A. and Lee, T.S. (2007). Screening of antibacterial and antifungal activities from Korean wild mushrooms. World J. Agric. Sci., 3(3): 316-321.

Jones, M. D.; Durall, D. M and Tinker, P. B. (1991). Fluxes of carbon and phosphorus between symbionts in Willow ectomycorrhizas and their changes with time. New Phytology, 119:99-106.

Kanchanaprayudh, J.; Zhou, Z; Yomyart, S.; Sihanonth, P.; Hogestu, T. and Watling, R. (2003). A new species, Pisolithus abditus, an ectomycorrhizal fungus associated with dipterocarps in Thailand. Mycotaxon, 88: 463-467.

Khan, Md. H.; Meghvansi, K. M.; Panwar, V.; Gogoi, K. H. and Singh, L. (2010). Arbuscular mycorrhizal fungi-induced signalling in plant defence against phytopathogens. Journal of Phytology, 2(7):53-69.
Martin, F.; Diez, J.; Dell, B. and Delaruelle, C. (2002). Phylogeography of the ectomycorrhizal Pisolithus species as inferred from nuclear ribosomal DNA ITS sequences. New Phytology, 153:345-357.

Montenegro, R. C.; Jimenez, P. C.; Farias, R. A. F.; Andrade-Neto, M.; Bezerra, F. S.; Moraes, M. E. A.; De Moraes, M. O.; Pessoa, C and Costa-Lotufo, L. V. (2004). Cytotoxic activity of pisosterol, a triterpene isolated from Pisolithus, Nature of Forest, 59(7-8):519-522.

Praveen Kumar, P.; Kumaravel, S. and Lalitha, C. (2010). Screening of antioxidant activity, total phenolics and GC-MS study Vitax negundo. African Journal Biochemistry Res., 4(7):191-195.

Reddy, M. S.; Natarajan, K. and Senthilarasu, G. (2005). Pisolithus indicus, a new species of ectomycorrhizal fungus associated with Dipetrocarps in India. Mycologia, 97(4):838-843.

Sebastiana, M.; Da Silva, A.B. and Matos, A.R. (2018). Ectomycorrhizal inoculation with Pisolithus tinctorius reduce stress induced by drought in cork oak. Mycorrhiza, 28:247-258.

Shrestha, G. V.; Shrestha, K. and Wallander. H. (2005). Antagonistic study of ecomycorrhizal fungi isolated from Baluwa forest (central Nepal) against pathogenic fungi and bacteria. Scientific World, 3(3):49-52.

Smith, S.E. and Read, D. J. (1997). Mycorrhizal symbiosis. 2nd ed. London: Academic Press, London, UK.p605.

Waser, S. P. (2002). Review of medicinal mushrooms advance: Good news from old allies. Herbal gram. American Botanical Council, 56:2833.

Watling, R.; Taylor, A.; Lee, S. S.; Sims, K and Alexander, I. (1995). A rainforest Pisolithus; its taxonomy and ecology. Nova Hedwigia Kryptogamenkd, 61:417-429.

Wilcox, H. E.; Waisel, Y and Kafkafi, U. (1991). The Plant Root, the Hidden Half. Marcel Dekker, New York, pp:731-765.

Zaat, S.A.J.; Wijffelman, C. A.; Spaink, H. P.; Van Brussel, A. A. N.; Okker, R. J. H. and Lugtenberg, B. J. J. (1989). Analysis of the major inducers of the Rhizobium nodA promoter from Vicia sativa root exudates and their activity with different nod D genes. J. Pl. Mol. Biol., 13:175188 .

Zamuner, M.; Diogenes, A.; Corteza, G and Benedito, Dias Filhob, P.M and Filho, E. R. (2005). Lanostane triterpenes from the Fungus Pisolithus tinctorius. J. Braz. Chem. Soc., 16(4):863-867.

Zeng, S.R.; Mallik, U.A and Setlife, E.D. (2003). Growth stimulation of ectomycorrhizal fungi by root exudates of Brassicaceae plants: Role of degraded compounds of Indole glucosinolates. J. Chem. Ecol., 29(6): 1337-1355. 